\title{
GENDER, CULTURE, AND THE INDIAN ORGANIZATION: REVIEWING CRITICAL VOIDS IN INDUSTRIAL ECONOMICS
}

\author{
Meher Sarna \\ The Shri Ram School Moulsari \\ DOI: 10.46609/IJSSER.2020.v05i09.009 URL: https://doi.org/10.46609/IJSSER.2020.v05i09.009
}

\begin{abstract}
The discipline of Economics has, over time, evolved to incorporate Industrial Economics as a unique and contextual field of inquiry and practice, incorporating insights not only from the structures and functioning of firms and markets, but also the constitution of such firms in different cultural, social, and political contexts around the world. In extension, thus, this has come to mean understanding the leadership of firms, their organizational practices, their business methods, their very own entity - in this form laying claim to their legacy of corporate personhood, under the guardianship of stewards who often benefit from biased and longstanding cultures of masculinity, patriarchy, and gendered operational notions of efficiency and productivity. This paper thus hopes to understand and deconstruct corporate culture, reviewing in the specific Indian context critical voids in the existing theoretical frameworks surrounding the industrial organization within the study of economics. By locating critical elements of gender and culture within these popular discourses, it aims to diversity the same and foster a greater factor of scholarly differentiation - primary hoping for an ability to gain more inclusive and allround understandings of economics as it exists at the base and substructural levels of the capitalist economy.
\end{abstract}

Keywords: Gender, Culture, constitution ,Economy ,Polity.

\section{Introduction}

The discipline of Economics has, over time, evolved to incorporate Industrial Economics as a unique and contextual field of inquiry and practice, incorporating insights not only from the structures and functioning of firms and markets, but also the constitution of such firms in different cultural, social, and political contexts around the world. This has included the consideration of calls for diversity that have existed for decades past, but have now achieved cognizance following the work of feminist movements across the globe, and their aim for accurate representation - representation as proxy and re-presentation as portrait, as posited by the 


\section{International Journal of Social Science and Economic Research}

ISSN: $2455-8834$

Volume:05, Issue:09 "September 2020"

subaltern scholar, Gayatri Chakravorty Spivak (Spivak, 2003). In extension, thus, this has come to mean understanding the leadership of firms, their organizational practices, their business methods, their very own entity - in this form laying claim to their legacy of corporate personhood, under the guardianship of stewards who often benefit from biased and longstanding cultures of masculinity, patriarchy, and gendered operational notions of efficiency and productivity.

This paper thus hopes to understand and deconstruct corporate culture, reviewing in the specific Indian context critical voids in the existing theoretical frameworks surrounding the industrial organization within the study of economics. By locating critical elements of gender and culture within these popular discourses, it aims to diversity the same and foster a greater factor of scholarly differentiation - primary hoping for an ability to gain more inclusive and all-round understandings of economics as it exists at the base and substructural levels of the capitalist economy. The paper reviews critical literature with regards to economics and associated fields, including aspects of sociological and corporate meanings behind representation. It takes such representation and also understands the importance, from an intersectional perspective, for an understanding of gender that is culturally rooted - specifically in the Indian context.

By doing so, it aims to not only understand the existing limitations behind the effective representation of women in Indian companies and their leadership, but also promote masculine structural forms within such organization - it aims to rethink the ways in which Human Resource practices that recruit human capital are imagined with respect to hiring and firing, and hopes to critique our conventional understandings of economic value as a whole.

The essay, however, is written cognizant of the inherently exclusive and exploitative nature of industries and firms within capitalist systems, and hopes to apply a nuanced perspective in characterizing such economic value in a manner that is relevant, plausible, and pragmatic in Indian markets, with respect to long-term and sustainable change of organizational practices.

In this manner, the paper considers the ways in which industrial economics as a discipline has failed women - whether with the incidence of sexual harassment on a global scale, the normalization of sexist behavioral practices within the office structure, and industry-specific differences in the methods in which norms and practices are formalized within both corporate culture as well as the observation and analysis of firms within economics (Barker \& Feiner, 2009). By doing so, and providing recommendations for future scholars, corporations and the representatives of such corporate structures and institutions, this paper hopes to be a small step forward in the rebellious journey towards an equality that isn't achieved as an event, but viewed, reviewed, imagined, and reimagined as a continuous process of introspection, retrospection, and change. 
International Journal of Social Science and Economic Research

ISSN: 2455-8834

Volume:05, Issue:09 "September 2020"

\section{Literature Review}

An understanding of the gendered existence of economics with respect to the firm needs a clarified understanding of industrial economy in the first place - its theories, objects (and subjects) of analysis, and a critical historiography of such analysis. Considering industrial economics, there is a need to look into the theory of the firm as it presently exists. Industrial economics falls prey to the practice of universally possessing objects of analysis, but few subjects, removing all sense of autonomy, dynamics identity, and context of such understandings (Waring and Steinem, 1988). Thus, industrial economics' assumption of ground-level complications to a perfectly competitive model, including theories such as the entry and flow of capital, imperfect competition, transaction costs, market organization and government interventions and actions are thus devoid of a deeper, more intrinsic comprehension of the composition of such organizations and 'objects' of study (Waring and Steinem, 1988). Perhaps, in this sense, industrial economics can be considered to objectify -- an intentional parallel raised here to the objectification of the non-male body in gendered social relations -- the institutions and organizations, industries, firms, and other beings of corporate existence into a voiceless, stewardship-requiring, corporate person who is incapable of being constituted in a complexity that includes gendered complexity (Manivannan \& Mohan, 2020).

Considering the different approaches taken to industrial economics - exists the microeconomic approach, with models including those understanding the internal organization with regards to market strategy, renewal, economic laws, and governance with regards to organizational infrastructure (Barker \& Feiner, 2009). Besides this, game theoretical approaches to industrial economics has resulted in a touch of interdisciplinarity being accorded to it, including aspects of behavioral economics, antitrust, and competition. It is only in this region of industrial economics that one begins to see what one can also term as the 'economic subaltern' speaking, representing, re-presenting, and having a say in the resistance against all that is universal, homogenous, voiceless, and opaque (Manivannan \& Mohan, 2020).

Now, considering the field of feminist economics which has emerged over the past few decades, gaining greater importance now in not simply better understanding and reimaging growth from feminist perspectives, but understanding the most basic foundations in which the discipline itself has been built - including rationality, the assumption of the reasonable man, market efficiency, and competition (Barker \& Feiner, 2009). There have been multiple theories that have emerged regarding the invalidity of the assumption of economic rationality, including the consideration of a utilitarian happiness maximization assumption, or even the consideration that rationality is an ungendered concept (Waring and Steinem, 1988). 


\section{International Journal of Social Science and Economic Research}

ISSN: $2455-8834$

Volume:05, Issue:09 "September 2020"

Scholars have argued the inherently masculine nature of rationality, rooted in binary, mathematical and numerical modes of understanding labour, growth, and investment, that is often unmindful of other forms of unpaid care, domestic labour, and care economics that have been stated by international governmental bodies including the UN to play a critical role in the maintenance of global economies (Manivannan \& Mohan, 2020; Barker \& Feiner, 2009).

Moving further, with respect to corporate culture in the Indian context, the lack of representation is not a fact that requires much justification, it nearly being a universally known and agreed upon fact that women (or more inclusively, non-men) in the workplace and their very existence is a discursive site of dissent, resistance, and rebellion (Sunder, 1996). The need of the hour is to now identify spaces for such dissent in a disciplinary sense.

\section{Discussion and Analysis}

What structural barriers that prevent the influx and upward mobility of non-men in corporate spaces? What relevance does this have to industrial economics which often functions via a macroeconomic perspective, not even viewing individual organization but "firms" which have a set of static characteristics? In this light, there are multiple levels of analysis to be considered -i) structural ii) microcosmic iii) queer and iv) feminist. While there are significant overlaps between these different levels of analysis, they serve as useful markers in this attempt to declassify, deconstruct, and reimagine industrial economics both in theory and practice.

From the structural perspective, the primary voids in the discipline include the lack of consideration of forms of active and passive discrimination with regards to both cultural diversity within the firm, gendered diversity within the firm, and demographic diversity within the firm, despite multiple scholars and studies establishing the benefits of diversity to the overall productivity, efficiency, and market supremacy of the firm (Sunder, 1996).

Furthermore, the lack of effective policies to regulate such discrimination is not a consideration within the field of industrial economics, nor is the widespread existence of masculine workplace practices - whether it be the disincentivization of the "loud woman", stereotypes in the workplace including sexist roles assigned to the woman including adjectives such as "crazy", "emotional", and the perpetual consideration of the female worker as sub par to the masculine standards she is expected to adhere to (Manivannan \& Mohan, 2020).

From a microcosmic perspective, one can consider aspects such as the lack of paid menstrual leave in most organizations, the lack of effective maternal and paternal leave, and additionally the largescale incidence of sexual harassment in the Indian corporate sphere (Kaushik, Sharma, and Kaushik, 2014). Despite the existence of the Sexual Harassment in the Workplace Act 2013, coming into being after widespread feminist movements and committes, including the 


\section{International Journal of Social Science and Economic Research}

ISSN: $2455-8834$

Volume:05, Issue:09 "September 2020"

SAKSHAM committee and the Vishakha Guidelines and years of feminist jurisprudence, sexual harassment continues to exist in large amounts, with a lack of public data regarding the numbers of such complaints, and with a lack of effective practices to ensure the implementation and establishment of Internal Complaints Committees (ICCs) according to the law in Indian offices with more than 10 employees. This is made worse by the lack of existence of Local Complaints Committees (LCCs) as a whole in most districts in India (Kaushik, Sharma, and Kaushik, 2014).

From a queer perspective, it is impossible to understand the voids in industrial economics without looking beyond the gender binary. If the lack of representation of women in organizations is of chief importance, the lack of representation and active inclusion of non-binary individuals is of far far greater concern, with there being no legal or clear corporate practices or rules to regulate the fair treatment of non-binary individuals, except for the existence of the Transgender Persons Act 2019 which most queer communities and trans-groups across the country openly opposing due to its policing of the transgender body, the existence of oppressive screening committees, and the designation of transgender individuals as subpar citizens by placing them under the threat of active guardianship. Perhaps the democratization and emancipation of the "firm" which can only function with guardians, can be considered as a parallel to the inclusion and emancipation of the transgender body, as per oppressive existing Indian laws (Kaushik, Sharma, and Kaushik, 2014).

Finally, from a feminist perspective, it is important to reorganize the discipline to not only include unpaid care labour and the care economy into existing considerations of growth, but to actively consider what many feminist economics consider to be "degrowth", to move away from narratives of growth that are bounded by capitalist notions of time, to consider instead care labour that is more organic, rooted with the flow of the day yet intensive nonetheless, and the backbone of a critical body of individuals who aren't simply future or past members of a labour pool (childcare and eldercare) but who are individuals with unique decision making aspects, and political, social, and legal autonomy and prowess (Manivannan \& Mohan, 2020).

\section{Conclusion}

The contemporary Indian organization needs to engage in the individual citizen's equivalent of therapy and introspection. The glorification of masculinized work and brawn-based cultures must give way to most feminist and inclusive forms of degrowth, to consider instead not only market competition but market collaboration (Sunder, 1996). There exists a heightened need for systems of checks and balances independent of higher organization, to consider industrial economics that operates in a manner that includes perspectives from the bottom-up, and not simply the top-down (Manivannan \& Mohan, 2020). 


\section{International Journal of Social Science and Economic Research}

ISSN: $2455-8834$

Volume:05, Issue:09 "September 2020"

It is only with the removal of these structural barriers can there be a true opening up of the field, in both the ways corporations and firms function and the ways in which they are studied and critiqued, to have economic reform in meaningful and sustainable manners. This needs to be coupled with effective governance and legal safeguards, including implementation of rules regarding sexual harassment prevention, gendered inclusion, and diversity in the workplace (Manivannan \& Mohan, 2020). By doing so, organizations and corporate structure can better find their place within larger societies, to truly be socially responsible, and better reform their own systems in a manner that is not simply driven by narratives of progress, development, and growth, but of change, inclusivity, and democracy.

\section{Bibliography}

Barker, Drucilla, and Susan F. Feiner. Liberating economics: Feminist perspectives on families, work, and globalization. University of Michigan Press, 2009.

Ferguson, Paul R., and Glenys Ferguson. Industrial economics: issues and perspectives. NYU Press, 1994.

Gherardi, Silvia. "Feminist theory and organization theory: A dialogue on new bases." The Oxford handbook of organization theory. 2003.

Kaushik, Neeraj, Anita Sharma, and Veerander Kumar Kaushik. "Equality in the workplace: a study of gender issues in Indian organisations." The Journal of Management Development 33.2 (2014): 90-106.

Manivannan, Srivatsan, and Deepanshu Mohan. "Examining China and India's Path to a Gender(Im) Balanced Growth: Reflections from the Post-Reform Eras." China-India Relations. Springer, Cham, 2020. 157-182.

Spivak, Gayatri Chakravorty. "Can the subaltern speak?." Die Philosophin 14.27 (2003): 42-58. Strober, Myra H. "Rethinking economics through a feminist lens." The American Economic Review 84.2 (1994): 143-147.

Sunder, Madhavi. "In a "Fragile Space": Sexual Harassment and the Construction of Indian Feminism." Law \& Policy 18.2-3 (1996): 419-442.

Waring, Marilyn, and Gloria Steinem. If women counted: A new feminist economics. San Francisco: Harper \& Row, 1988. 